\title{
Characteristics and magnitude of sea turtle bycatch in US mid-Atlantic gillnet gear
}

\author{
Kimberly T. Murray* \\ NOAA Fisheries, Northeast Fisheries Science Center, 166 Water Street, Woods Hole, Massachusetts 02543, USA
}

\begin{abstract}
From 1995 to 2006, US federal fisheries observers deployed aboard commercial fishing vessels in the US mid-Atlantic region documented captures of loggerhead Caretta caretta, green Chelonia mydas, Kemp's ridley Lepidochelys kempii, and leatherback Dermochelys coriacea turtles in commercial sink gillnet gear. Data collected by these observers were used to characterize sea turtle bycatch in sink gillnet gear, including the temporal and spatial distribution, fishing characteristics, species composition, and sizes of turtles captured. In addition, these data were used to develop a generalized additive model to evaluate and predict bycatch rates (turtles per metric ton of fish landed) of sea turtles. These rates were then applied to commercial gillnet landings over the same time period to estimate total bycatch of loggerhead turtles. Bycatch rates of loggerheads were correlated with latitude, sea surface temperature, and mesh size. Highest predicted bycatch rates occurred in warm waters of the southern mid-Atlantic, in large-mesh gillnets. From 1995 to 2006, the average annual bycatch estimate of loggerheads was 350 turtles (coefficient of variation $=0.20,95 \%$ CI over the $12 \mathrm{yr}$ period: 234 to 504). Characteristics and magnitude of bycatch can help inform population assessments, while the distribution of bycatch rates can be used to help inform bycatch mitigation options.
\end{abstract}

KEY WORDS: Sea turtle · Bycatch · Gillnet - Generalized additive model · GAM · Atlantic · Mitigation

Resale or republication not permitted without written consent of the publisher

\section{INTRODUCTION}

Bycatch of sea turtles in commercial fishing gear is a conservation problem demanding innovative solutions for mitigation. Fisheries bycatch is one of many factors negatively affecting turtle populations (Lewison \& Crowder 2007). Assessing both the distribution of turtle bycatch and factors influencing bycatch rates can help identify areas of elevated risk of bycatch (Gardner et al. 2008, Sims et al. 2008). In some cases fishing effort can be steered away from these bycatch 'hotspots', so that fishing can continue while minimizing the potential for turtle bycatch (Howell et al. 2008). Furthermore, understanding fishing gear characteristics that influence bycatch or bycatch rates can help lead to gear modifications designed to reduce bycatch (Haas et al. 2008).

In the US mid-Atlantic region, an estimated several hundred turtles have been captured in trawl and scal- lop dredge gear over the past decade (Murray 2004, 2005, 2006, 2007), and additional turtle captures have been documented in other gear types, such as pound nets and sink gillnets. In the greater western North Atlantic area, turtles have also been captured in pelagic longline fisheries (Witzell 1999, Brazner \& McMillan 2008, Fairfield \& Garrison 2008). The 4 turtle species that typically occur in mid-Atlantic waters, loggerhead Caretta caretta, green Chelonia mydas, Kemp's ridley Lepidochelys kempii, and leatherback Dermochelys coriacea, are listed as either threatened or endangered under the US Endangered Species Act (ESA). Both loggerheads and green turtles are considered Endangered according to the International Union for Conservation of Nature's (IUCN) Red List (Marine Turtle Specialist Group 1996a, Seminoff 2004), and the leatherback and Kemp's ridley turtles considered Critically Endangered (Marine Turtle Specialist Group 1996b, Sarti Martinez 2000). 
Some conservation measures are already in place for mid-Atlantic fisheries. For example, various gillnet regulations have been implemented in federal waters to minimize gear interactions with protected species or to manage fish stocks. These regulations include measures such as seasonal and/or area closures, gear or fishing restrictions, and commercial quotas. For instance, since May 2000, federal waters in the southern mid-Atlantic have been closed seasonally to largemesh gillnets, defined at various times to be $>15.2 \mathrm{~cm}$ (6 inches), $17.8 \mathrm{~cm}$ (7 inches), or $20.3 \mathrm{~cm}$ (8 inches) (US Department of Commerce 2002a). Additionally, sea turtle conservation measures have been implemented in some US state waters. Since September 2002, portions of Pamlico Sound, NC have been closed from September 1 to December 15 to gillnets with a mesh size $>10.8 \mathrm{~cm}$ (4.25 inches) stretched mesh (defined as the distance between the centers of 2 opposite knots in the same mesh when pulled taut; 50 US Code of Federal Regulations [CFR] 222.102) (US Department of Commerce 2002b).

From 1995 to 2006, fisheries observers in the midAtlantic documented captures of loggerhead, green, Kemp's ridley, and leatherback turtles in sink gillnet gear. To date, the characteristics, rates, and total magnitude of sea turtle bycatch in gillnet gear in the midAtlantic region have not been examined in detail. Understanding the factors that affect bycatch rates would be very helpful in identifying conservation options. Furthermore, understanding the magnitude, species, and size composition of turtles caught in gillnet gear will improve assessments of bycatch across multiple gear types, and provide a baseline to evaluate mitigation implementation and enforcement (Lewison \& Crowder 2007, Moore et al. 2009).

The purposes of this paper are to: (1) describe characteristics of observed sea turtle bycatch in sink gillnet gear; (2) evaluate environmental variables and fishing practices correlated with bycatch rates of loggerhead sea turtles; and (3) estimate and report the total average annual loggerhead bycatch in US mid-Atlantic sink gillnet fisheries.

\section{MATERIALS AND METHODS}

Study region. Data collected by Northeast Fisheries Science Center observers deployed aboard commercial gillnets during the period 1995 to 2006 were analyzed to derive loggerhead bycatch rates, expressed as the number of observed turtles per metric ton of fish landed. These rates were then applied to total commercial gillnet landings over the same time period to estimate the average annual bycatch of loggerheads in US mid-Atlantic sink gillnet fisheries.

All observed turtle captures occurred in the midAtlantic region, although substantial observer effort also occurred throughout the year east of Cape Cod and in the Gulf of Maine during 1995 to 2006 (Fig. 1a). During this period, $>50 \%$ of observed gillnet hauls from Maine to North Carolina (NC) occurred east of Cape Cod and in the Gulf of Maine, but no turtle captures were observed. Because observed turtle bycatch in US Atlantic commercial gillnet fisheries during 1995 to 2006 was limited exclusively to the mid-Atlantic region, a gillnet bycatch estimate was derived only for
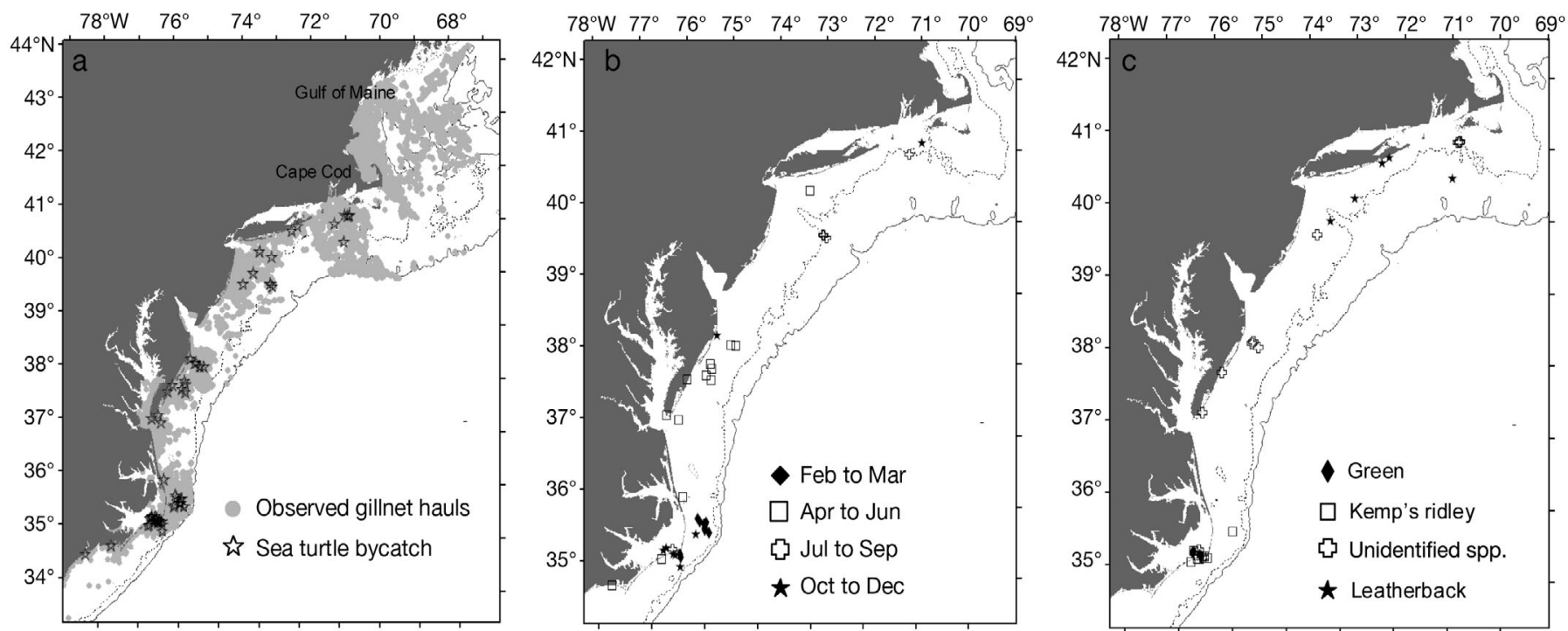

Fig. 1. Locations of observed sink gillnet hauls, 1995 to 2006. (a) Observed hauls and turtle bycatch; (b) observed loggerhead Caretta caretta bycatch; (c) observed green Chelonia mydas, Kemp's ridley Lepidochelys kempii, unidentified, and leatherback Dermochelys coriacea turtle bycatch. The $50 \mathrm{~m}$ (dotted) and $200 \mathrm{~m}$ (solid) bathymetry lines are also shown 
the mid-Atlantic. In this study, the mid-Atlantic is explicitly defined as west of $70^{\circ} \mathrm{W}$ from the shoreline of Cape Cod southward to the southern limit of the observer data collection program $\left(\sim 33^{\circ} \mathrm{N}\right)$, extending westward to the coastline.

Data sources. Observer data: Gillnet data used in this analysis were obtained from gillnets that were either anchored to the bottom ( $96 \%$ of hauls), or unanchored but fishing on the ocean bottom ( $4 \%$ of hauls). Both anchored and unanchored gillnets are considered sink gillnets (Steve et al. 2001). Sink gillnets are typically composed of a series of net panels strung together in a line. Based on information collected by observers from 1995 to 2006, panels generally measure $3 \mathrm{~m}$ high by $91 \mathrm{~m}$ long, and when strung together range from 91 to $1524 \mathrm{~m}$ in total length. In the mid-Atlantic, mesh sizes typically range between $\sim 5$ and $35.6 \mathrm{~cm}$, with the choice of mesh size dictated by season, water depth, location, and target species (Steve et al. 2001). Soak times range between $<1 \mathrm{~h}$ and $\sim 5 \mathrm{~d}$. For bottom-dwelling species such as flatfish and monkfish, 'tie-downs' are often used, whereby the float and leadline are tied together to create a bag in the net to target the catch more efficiently.

From 1995 to 2006, a total of 6705 trips were observed in mid-Atlantic gillnet fisheries, encompassing 32984 hauls (Table 1). Observer coverage ranged between $\sim 1$ and $5 \%$, and was highest in 1995 and lowest in 2002. Observer data included characteristics of each trip, gear set, and haul, including information on kept and discarded fish catch and incidental bycatch of protected species.

Commercial data: Three sources of commercial landings data were used in this analysis: vessel trip reports (VTRs), dealer landing reports, and North Carolina Division of Marine Fisheries (NCDMF) data. The approach used to determine total commercial gillnet landings in the mid-Atlantic is described next.

VTRs: All federally permitted vessels operating under Fishery Management Plans (FMPs) implemented by the National Marine Fisheries Service (NMFS) Northeast Region are required to complete VTRs providing information on fishing location, fishing effort (i.e. days fished, days absent, etc.), and some gear characteristics (i.e. mesh size) for each fishing trip (Rago et al. 2005). Normally, the captain of any federally permitted vessel (with the exception of vessels possessing only a federal lobster permit) selling its catch to a federally permitted dealer is required to submit a VTR record, regardless of the species caught. If non-federally regulated species are sold and the vessel does not possess a permit for a federally regulated species, a logbook record is not required to be filed. Mandatory reporting in some federal fisheries began in April 1994; by 1998, most federally managed fisheries had mandatory VTR requirements.
Dealer-reported landings: All dealers who buy and sell fish regulated by federal FMPs are required to report $100 \%$ of their transactions (Rago et al. 2005). Thus, the landings data in the dealer database can be considered to be a near census of total fishery landings; however, unlike VTR reports, the dealer reports do not contain information on fishing location, fishing effort, or mesh size.

NCDMF: Because the state of NC does not report all of its landings to the Northeast dealer database (Palka \& Rossman 2001), commercial landings data from this state were obtained from the NCDMF trip ticket program. NCDMF data included landings from federal waters ( $>3$ nautical miles [ $>4.8 \mathrm{~km}$ ] from shore), as well as landings from state waters including the main body of Albemarle and Pamlico Sounds, and waters 0 to 3 nautical miles ( 0 to $4.8 \mathrm{~km}$ ) from shore. Landings from rivers and tributaries, however, were excluded from the analysis.

Methods used to compile commercial data set: VTR data were the primary data used in estimating total bycatch because most VTRs contained the necessary information on fishing location and characteristics (i.e. mesh size) necessary to derive total bycatch in this analysis. However, a comparison of VTR landings with Northeast dealer and NCDMF landings from midAtlantic state and federal waters revealed that $>50 \%$ of the commercial gillnet landings were not reflected in the VTR database. Therefore, VTR landings were adjusted upwards to equal the landings reported in the Northeast Region dealer database for all states except $\mathrm{NC}$, where landings were adjusted upwards based on the NCDMF data.

To adjust VTR data to match the magnitude of landings in the dealer data, VTR and dealer landings were first totaled by strata, $i$ (which in this case was each state). Next, an adjustment factor (AF) for each stratum was calculated as:

$$
\mathrm{AF}_{i}=\frac{\sum \text { Dealer landings }_{i}}{\sum \mathrm{VTR}_{\text {landings }}}
$$

where $i=$ state in which catch was landed.

For each VTR trip in stratum $i$, the landed catch was multiplied by the AF of stratum $i$. Trips from Delaware had the highest AF (49.7), though these trips accounted for only $0.1 \%$ of total gillnet fishing effort in the mid-Atlantic. Excluding Delaware, AFs ranged between 0.2 and 6.9 (mean $=2.2$ ) for each state, with the highest for trips from NC.

Sea surface temperature (SST) data: For VTR trips and observed hauls where SST data were missing $(7 \%$ of hauls), SST data were obtained from $5 \mathrm{~d}$ composites derived from AVHRR Pathfinder Version 5, Modis Aqua, Modis Terra, or GOES satellites, or 5 d climatology images downloaded from NASA's Jet Propulsion 
Laboratory (Warden \& Orphanides 2008). Preliminary analyses revealed that SST obtained from satellite data in the NC area was biased high compared to temperatures recorded by observers. Off $\mathrm{NC}$, satellite-derived SST averaged $\sim 2$ to $4^{\circ} \mathrm{C}$ warmer than observerrecorded SST at the same location, as opposed to a difference of $\leq 1^{\circ}$ for other states. Due to the effects of the Gulf Stream in the NC area, large temperature differences over small spatial scales can cause remotely sensed SST to be an imprecise measure of SST at specific haul locations. Therefore, for observed hauls with missing SST in NC $(<1 \%)$, or for VTR trips operating in NC $(<10 \%)$, SST was predicted from observerrecorded temperatures based on statistical area and month $\left(\mathrm{R}^{2}=0.90, \mathrm{n}=62343\right)$.

Analytic approach. Estimation of bycatch rates: Bycatch rates of loggerhead turtles were estimated using a generalized additive model (GAM) in which bycatch rates were evaluated in relation to fishing practices and environmental variables. A modeling approach could not be taken to estimate bycatch rates of other turtle species (Kemp's ridley, green, leatherback, and unidentified) due to the relatively low number of observations. Because the rarity of observed turtle captures limits the amount of information available to fit complex models (McCracken 2004), care was taken in selecting variables. Statistical rules of thumb suggest there should be at least 10 observations of the rarest event per parameter considered in the model (Stokes et al. 1995, Peduzzi et al. 1996, Harrell 2001). Using this rule of thumb, a model of loggerhead bycatch would support $\sim 4(41 / 10)$ parameter estimates.

Bycatch model: Bycatch rates were expressed as:

$$
R=\frac{\text { Number of observed turtles }}{\text { Metric tons of observed landings }}
$$

The preferred measure of fishing effort in gillnet bycatch analyses is landings (or kept catch), as landings data are generally recorded and available for the entire fishery (Palka \& Rossman 2001). Furthermore, in the observer data used here there is a relationship between the number of loggerhead bycatch and observed metric tons landed (i.e. the number of loggerheads increases as average landings increase). Soak length, defined as the amount of time a net is soaking in the water multiplied by the length of the net, was also explored as a potential unit of effort. An examination of fields to derive soak length in the VTR data, however, revealed that there were too many inaccuracies in the information reported to use this unit of effort in the bycatch analysis.

A GAM with a Poisson distribution (GAM function, SPLUS 7.0) was used to model the expected turtle bycatch rate. The general form of a GAM can be written as:

$$
Y=\alpha+\sum_{j=1}^{n} f_{j}\left(X_{j}\right)+\xi
$$

where $Y$ is the dependent variable (log-transformed turtle bycatch per metric ton of landings), $\alpha$ is an intercept term, $f_{j}$ is a series of smoothing functions, $X_{j}$ are predictor variables describing environmental or fishing characteristics, and $\xi$ is unexplained error (Hastie \& Tibshirani 1990).

Model selection process: Seven variables were considered in the model selection process: 5 primary variables (SST, latitude, depth, mesh size, hang ratio of the net) and 2 secondary variables (year or year group, and target species). Hang ratio is a measure of how tightly the net is stretched along the float line and lead line, and reflects the degree of slack in the net. Year was considered individually ( $\mathrm{n}=12 \mathrm{yr}$ ), and also as 2 groups (1995-1999 and 2000-2006), because significant changes occurred in gillnet regulations for some fisheries beginning in early 2000. Other variables were initially considered (longitude, distance of haul from coast, distance of haul from $20 \mathrm{~m}$ bathymetry line, month or calendar quarter, bottom temperature, SST fronts, chlorophyll concentration, and use of tiedowns); but these were omitted from model selection due to either a large proportion of missing data (i.e. $>10 \%$ ), or correlations amongst the variables.

Observers documented a total of 53 different target species in the gillnet fisheries. To have sufficient statistical power to investigate the relationship between target species and bycatch rates, the target species were grouped into 4 categories: monkfish (23\% of observed hauls), Atlantic croaker (19\%), spiny dogfish (9\%), and all other species $(n=50$ species; $49 \%$ ). The first 3 groups were the most frequent and the fourth group comprised the remaining observations.

The 5 primary variables were tested in a forward stepwise model selection process (step.gam function, SPLUS 7.0). The null model consisting of the overall mean was the initial model in the stepwise procedure. At each step, the forward stepwise algorithm selected the variable that generated the greatest change in the Akaike information criterion (AIC) relative to all other model variables. All continuous variables were considered as smooth terms in the model using the default degrees of freedom in the fitting procedure. If a variable did not decrease the AIC by 7 , that variable was not included in the model (Burnham \& Anderson 2002).

GAM curves from the selected model were then examined to assess the relationship of each variable to the estimated bycatch rate. GAM curves summarize the trend of a response measurement as a function of 1 or more predictor measurements (Hastie \& Tibshirani 1990). Variables demonstrating close to a linear relationship with the bycatch rate were re-entered in the 
model selection process as both smooth and linear terms. The stepwise model selection process was then re-run to select the best-fitting form of the variable.

The secondary variables were tested separately at the end of the model selection process to determine if significant variability in bycatch rates remained unexplained by the best-fitting candidate model. Target species group was tested at the end of the model selection process because of possible colinearity with mesh size ( $86 \%$ of observed hauls $\geq 20.3 \mathrm{~cm}$ were targeting monkfish).

The final model was examined for overdispersion, a common problem with Poisson distributed data. Overdispersion occurs when the variance of a response is greater than the mean and is generally caused by positive correlation between responses, or by excess variation between response counts (Hardin \& Hilbe 2001). Overdispersion was measured by calculating the dispersion parameter $(\Phi)$, defined as:

$$
\Phi=\frac{\Sigma\left(y_{i}-\hat{\mu}_{i}\right)^{2} / \hat{\mu}_{i}}{\text { residual df }}
$$

An estimated dispersion value $>6$ indicates that the fitted model does not adequately account for enough variation in the data (Burnham \& Anderson 2002).

Estimation of bycatch magnitude: The final model was applied to the adjusted VTR landings data to derive an estimated loggerhead bycatch rate for each VTR trip, and to estimate the number of loggerheads caught on each VTR trip. Total annual estimated bycatch was the sum of the predicted number of turtles captured over all trips in a year.

Bootstrap resampling was used to derive a coefficient of variation $(\mathrm{CV})$ and $95 \% \mathrm{CI}$ for the average annual bycatch over the entire 1995-2006 period. Bootstrap replicates were generated by sampling hauls with replacement 1000 times from the original observer data set, and then the model fit to each replicate. Total estimated bycatch was then calculated by applying each replicate dataset to the adjusted VTR landings data. A CV and $95 \%$ CI were derived from the replicate bycatch estimates.

Exploration of sources of uncertainty. Choice of sampling unit: The sampling unit used in this analysis was the haul. Therefore, hauls were assumed to be independent of one another. If hauls are not independent (perhaps by being close to one another in time and space), an alternative sampling unit might be a fishing trip. Because the choice of a sampling unit may affect the predictive power of a model (McCracken 2004), the model selection process was also undertaken using trip (rather than haul) as the sampling unit. To assess whether overdispersion was effected by the sampling unit, the final model was also refit using trip as the sampling unit instead of haul. In the refit, each explanatory variable in the model was averaged over all hauls on a trip.
Representativeness of VTR data: VTR landings on each reported gillnet trip were adjusted upwards so that the total amount of VTR gillnet landings in the mid-Atlantic matched the total dealer-reported gillnet landings within the same geographical areas. This approach is appropriate if missing trip reports reflect the same environmental and gear characteristics as trip reports with this information. This may not be the case if, for instance, a disproportionate amount of missing trip reports are from inshore areas where waters may be warmer or cooler than offshore areas (depending on the time of the year).

To explore possible error introduced by filling in missing VTR data with patterns in known VTR data, missing data were filled in with observer data instead. That is, the 'missing' VTR landings in each stratum were derived using observed landings (rather than VTR landings) in that stratum, adjusted upwards to equal dealer landings in that stratum. This represents an alternative temporal and spatial distribution of landings. The percentage of landings in the VTR and observer data was then compared by month (across different mesh sizes and yearly time blocks) with both the dealer and NCDMF landings patterns to evaluate the representativeness of the VTR and observer data. The landings data developed in this second approach were then used to derive another estimate of the total annual bycatch of loggerhead turtles in mid-Atlantic gillnet fisheries.

\section{RESULTS}

Over the period 1995 to 2006, observers reported a total of 41 loggerhead turtles, 5 green turtles, 5 leatherback turtles, 8 Kemp's ridley turtles, and 13 unidentified species incidentally caught in mid-Atlantic gillnet gear (Table 1, Fig. 1b,c).

\section{Bycatch characteristics}

Temporal and spatial distribution

Loggerhead bycatch occurred in waters south of Cape Cod to NC in all months, except January. Fourteen $(34 \%)$ of the loggerhead captures occurred in March. Observers reported loggerheads in depths ranging between 1.8 and $76.8 \mathrm{~m}$ (mean $=28.0 \mathrm{~m})$, and in waters with SST ranging between 8.6 and $27.8^{\circ} \mathrm{C}$ $\left(\right.$ mean $\left.=17.2^{\circ} \mathrm{C}\right)$. Bycatch of green and Kemp's ridley turtles occurred south of $36^{\circ} \mathrm{N}$ from March through December in waters 2 to $38 \mathrm{~m}$ deep (mean $=9.0 \mathrm{~m}$ ), and with SSTs between 12.2 and $26.9^{\circ} \mathrm{C}$ (mean $=17.7^{\circ} \mathrm{C}$ ). Bycatch of leatherbacks occurred north of $39^{\circ} \mathrm{N}$ from 
Table 1. Observer coverage and observed turtles by year in mid-Atlantic sink gillnet gear. Obs. trips = observed trips; Obs. hauls $=$ observed hauls; Obs. tons $=$ observed metric tons of fish landed; AVTR tons $=$ adjusted vessel trip report (VTR) metric tons of fish landed; $\mathrm{OC}=$ percent observer coverage, expressed as: $($ Obs. tons $/ \mathrm{AVTR}$ tons $) \times 100 ; \mathrm{Cc}=$ Caretta caretta; Cm $=$ Chelonia mydas; Dc = Dermochelys coriacea $;$ Lk = Lepidochelys kempii; $\mathrm{Ui}=$ unidentified

\begin{tabular}{|lcccccccccc}
\hline Year & Obs. trips & Obs. hauls & Obs. tons & AVTR tons & OC (\%) & Cc & Cm & Dc & Lk & Ui \\
\hline 1995 & 483 & 2688 & 651.9 & 13198.7 & 4.9 & 4 & 0 & 0 & 0 & 0 \\
1996 & 431 & 2414 & 636.4 & 19656.1 & 3.2 & 4 & 0 & 0 & 0 & 0 \\
1997 & 442 & 2273 & 630.2 & 15665.2 & 4.0 & 1 & 0 & 0 & 0 & 3 \\
1998 & 677 & 3348 & 853.4 & 21393.9 & 4.0 & 6 & 2 & 0 & 4 \\
1999 & 583 & 2882 & 415.6 & 25192.1 & 1.6 & 13 & 0 & 0 & 1 \\
2000 & 596 & 3059 & 385.2 & 29753.6 & 1.3 & 4 & 1 & 0 & 2 \\
2001 & 645 & 2705 & 431.4 & 30647.2 & 1.4 & 4 & 0 & 0 & 0 \\
2002 & 351 & 1788 & 237.9 & 28365.7 & 0.8 & 0 & 0 & 0 & 0 \\
2003 & 365 & 1882 & 374.5 & 30483.2 & 1.2 & 1 & 0 & 1 & 0 \\
2004 & 697 & 3213 & 616.5 & 27758.8 & 2.2 & 3 & 1 & 3 & 0 \\
2005 & 703 & 3286 & 634.0 & 24497.8 & 2.6 & 1 & 1 & 0 & 0 \\
2006 & 732 & 3446 & 570.2 & 23345.4 & 2.4 & 0 & 0 & 1 & 1 \\
Total & 6705 & 32984 & 6437.1 & 289957.7 & 2.2 & 41 & 5 & 5 & 8 & 0 \\
\end{tabular}

July to December, in waters 18 to $68 \mathrm{~m}$ deep (mean $=$ $39.5 \mathrm{~m})$ and at SSTs between 12.2 and $21.1^{\circ} \mathrm{C}($ mean $=$ $\left.15.3^{\circ} \mathrm{C}\right)$.

Thirteen turtles could not be identified to species as they fell from the gear or swam away quickly and the observer did not have adequate time to positively identify the turtle. These unidentified turtles occurred from $35^{\circ} \mathrm{N}$ to $41^{\circ} \mathrm{N}$ from May to November in waters 5 to $38 \mathrm{~m}$ deep, and SSTs between 14.4 and $20.6^{\circ} \mathrm{C}$.

Fishing method and entanglement situations

Almost all ( $\mathrm{n}=40)$ loggerheads were captured in anchored sink gillnet gear. One was caught in unanchored sink gillnet gear. Loggerheads were captured in gillnets targeting monkfish ( $\mathrm{n}=25$ observed loggerheads), spiny dogfish $(\mathrm{n}=3)$, Spanish mackerel $(\mathrm{n}=3)$, southern flounder $(n=2)$, smooth dogfish $(n=2)$, striped bass $(n=1)$, Atlantic croaker $(n=1)$, unidentified flounder $(\mathrm{n}=1)$, summer flounder $(\mathrm{n}=1)$, king mackerel $(n=1)$, and unidentified sharks $(n=1)$. Mesh sizes of nets capturing loggerheads ranged between 7.6 and $30.5 \mathrm{~cm}$, with most $(\mathrm{n}=25)$ of the observed captures in $30.5 \mathrm{~cm}$ nets targeting monkfish. Sixteen loggerheads were captured in nets using tie-downs, and 25 without.

Bycatch of the other turtle species occurred in anchored sink gillnets targeting monkfish ( $\mathrm{n}=10)$, southern flounder $(n=4)$, king mackerel $(n=3)$, spiny dogfish $(\mathrm{n}=3)$, bluefish $(\mathrm{n}=3)$, summer flounder $(\mathrm{n}=$ $2)$, Spanish mackerel $(n=2)$, smooth dogfish $(n=1)$, black drum $(\mathrm{n}=1)$, kingfish $(\mathrm{n}=1)$, and weakfish $(\mathrm{n}=$ 1). These bycatches occurred in nets having mesh sizes between 3.3 and $30.5 \mathrm{~cm}$. Thirteen turtles were captured in nets with tie-downs, and 18 without.
Observers provided comments on 37 turtles (51\% of the 72 observed) describing how these turtles were positioned in the gear. Turtles were entangled (15 of 37 ), or not entangled (14 of 37), or fell from the gear as the net was being retrieved ( 8 of 37). Entangled turtles were captured in mesh sizes ranging between 9.1 and $30.5 \mathrm{~cm}$, and in nets with and without tie-downs. Nonentangled turtles were caught in mesh sizes ranging between 3.3 and $30.5 \mathrm{~cm}$, and those that fell from the net were in mesh sizes ranging between 8.9 and $30.5 \mathrm{~cm}$. There were no descriptions of turtles entangled in parts of the gear other than the net, such as the anchor, buoy, or tie-down lines.

\section{Turtle sizes}

Sizes (curved carapace length [CCL] from notch to tip) of the observed loggerheads caught ranged between 52 and $101 \mathrm{~cm}$ ( $\mathrm{n}=12$ turtles), with a mean of $65.3 \mathrm{~cm}$. Ten of the $12(83 \%)$ loggerheads measured were under $72 \mathrm{~cm} \mathrm{CCL}$, a size considered to be a juvenile life stage (NMFS and USFWS 2008). Of the 6 loggerheads reported as entangled, only 1 turtle was measured (90 cm CCL). Sizes of the observed Kemp's ridleys caught ranged between $\sim 28$ and $44 \mathrm{~cm} \mathrm{CCL,}$ while the size range of observed green turtles caught was between $\sim 28$ and $38 \mathrm{~cm}$ CCL. Observers did not measure any of the observed leatherbacks or unidentified turtles.

In a number of instances, size measurements could not be taken and observers estimated the length of the captured turtles $(\mathrm{n}=20$ loggerheads, $\mathrm{n}=1$ Kemp's ridley, $\mathrm{n}=3$ leatherbacks, $\mathrm{n}=8$ unidentified). For the hard-shelled turtles, length estimation occurred because the turtles fell from the net before coming on 


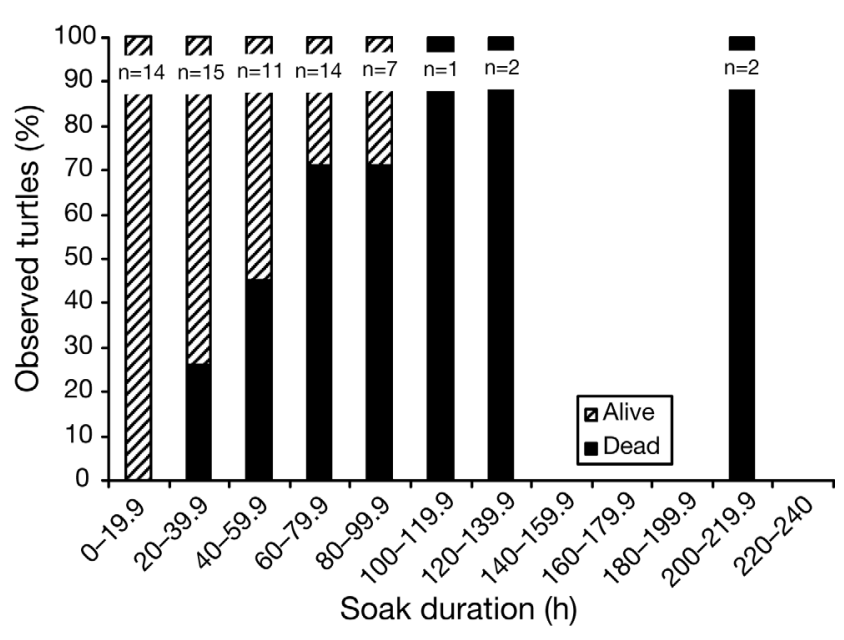

Fig. 2. Animal condition (alive or dead) of observed turtle bycatch (species as in Fig. 1) in sink gillnet gear in relation to the soak duration of the net

board. Although none of the estimated lengths are reported here, all but 1 estimated loggerhead lengths were in the range of the measured turtles, with the majority under $87 \mathrm{~cm}$ CCL (the lower range of the cutoff between sexually immature and mature loggerhead turtles; NMFS and USFWS 2008). Of the 3 leatherbacks with estimated lengths, 1 was severely decomposed, and 2 were not brought on board.

\section{Animal condition and soak duration}

Turtles were captured alive (52\%), dead $(40 \%)$, and in unknown condition $(8 \%)$ when observers could not adequately see the turtle. One Kemp's ridley was resuscitated on deck and swam away upon release. Soak times for gillnets in which live turtles were captured ranged between 0.6 and $96 \mathrm{~h}$ (mean $=29.6 \mathrm{~h}$ ), and between 22.2 and $216 \mathrm{~h}$ (mean $=80 \mathrm{~h}$ ) for gillnets in which fresh dead turtles were captured. As soak time increased, the percentage of observed live turtles decreased (Fig. 2). Two extremely decomposed leatherbacks were captured in nets soaking 72 and $114 \mathrm{~h}$, indicating these turtles may have died prior to capture, or long before being observed.

\section{Estimation of bycatch rates \\ Loggerhead bycatch model}

The best-fitting model of loggerhead bycatch rates in the mid-Atlantic sink gillnet fishery from 1995 to 2006 describes bycatch rates as a function of latitude, SST, and mesh size (Table 2). Cumulatively, these 3 variables explained $34 \%$ of the variation in observed bycatch rates. Mesh size explained the largest amount $(20 \%)$ of variation in bycatch rates. Latitude and SST were tested as either smooth or linear terms after examining GAM plots. The step.gam algorithm selected a linear form of latitude, and a smoothed form of SST. Hang ratio and depth reduced the AIC of the model by only a small amount (change in AIC of 3.4 and 0.8 , respectively), and thus these 2 variables were excluded from further model selection.

Target species group and year were not selected in the best-fitting model. Species group only explained an additional $2 \%$ of model variance over latitude, water temperature, and mesh size. The monkfish group and mesh size variable appeared correlated ('alias' function displayed a high collinear term [8] between these 2 variables in the final model), suggesting that the variation in bycatch rates in the monkfish group could be explained mainly by mesh size. Year also explained a relatively small amount of variance $(4 \%)$ in the model compared to latitude, water temperature, and mesh size. Estimated dispersion value of the final model (without target species or year) was 4.6, indicating that the model accounted for an adequate amount of variation in the data.

Table 2. Caretta caretta. Variables examined in analysis of factors affecting estimated bycatch rates of loggerhead turtles in gillnet gear. 'Secondary' variables were tested separately, after the best-fitting candidate model was selected. AIC $=$ Akaike information criterion; s = smoothed; SST = sea surface temperature; lat = latitude; mesh = mesh size

\begin{tabular}{|c|c|c|c|c|c|c|}
\hline Variables & Model structure & $\begin{array}{l}\text { Residual } \\
\text { df }\end{array}$ & $\begin{array}{l}\text { Residual } \\
\text { deviance }\end{array}$ & $\begin{array}{l}\text { Cumulative } \\
\% \text { of deviance } \\
\text { explained }\end{array}$ & $\begin{array}{c}\text { AIC } \\
\text { statistic }\end{array}$ & $\mathrm{p}\left(\chi^{2}\right)$ \\
\hline \multirow[t]{4}{*}{ Primary } & Null model only & 32983.0 & 590.8 & & 592.7 & \\
\hline & Null $+\mathrm{s}(\mathrm{SST})$ & 32979.1 & 536.2 & 9 & 546.0 & $<0.01$ \\
\hline & Null + s(SST) + (lat) & 32978.1 & 506.0 & 14 & 517.7 & $<0.01$ \\
\hline & Null + s(SST) + (lat) + s(mesh) & 32974.3 & 389.5 & 34 & 408.9 & $<0.01$ \\
\hline \multirow[t]{3}{*}{ Secondary } & Null $+\mathrm{s}(\mathrm{SST})+($ lat $)+\mathrm{s}($ mesh $)+($ target species $)$ & 32971.3 & 378.4 & 36 & 403.8 & 0.01 \\
\hline & Null $+\mathrm{s}(\mathrm{SST})+($ lat $)+\mathrm{s}($ mesh $)+\mathrm{s}($ year $)$ & 32970.3 & 367.7 & 38 & 395.0 & $<0.01$ \\
\hline & Null + s(SST) + (lat $)+s($ mesh $)+($ year group $)$ & 32973.3 & 378.0 & 36 & 399.5 & $<0.01$ \\
\hline
\end{tabular}


GAM smoothers indicated that higher bycatch rates occurred in southerly latitudes, and that bycatch rates increased with increases in SST and mesh size (Fig. 3). Predicted bycatch rates on VTR trips ranged between 0.0 and 5.2 loggerheads per metric ton landed (Fig. 4).

\section{Estimation of bycatch magnitude}

Applying the loggerhead bycatch model to total adjusted mid-Atlantic VTR landings resulted in an average annual bycatch estimate of 350 loggerhead turtles during 1995 to 2006 (CV $=0.20,95 \%$ CI over the $12 \mathrm{yr}$ period: 234 to 504$)$. The majority of average estimated bycatch ( $64 \%$ or $n=223 / 350$ ) occurred on $<2 \%$ of VTR trips $(\sim 3 \%$ of total landings) with high pre-
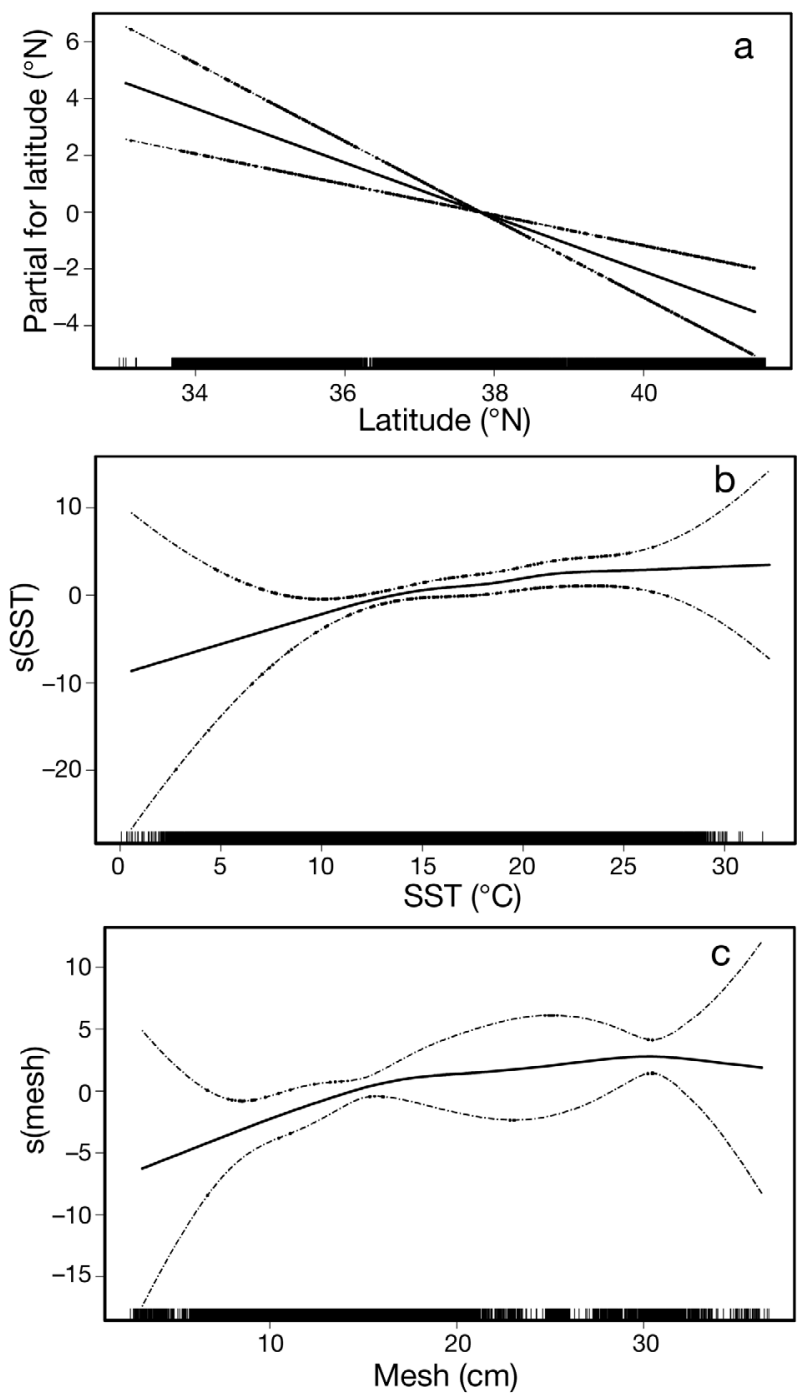

Fig. 3. General additive model smoothers depicting effect of (a) latitude, (b) sea surface temperature, s(SST), and (c) mesh size, s(mesh), on loggerhead Caretta caretta bycatch rates. Rugplot on $x$-axis shows no. of observations; dashed lines are \pm 2 SE confidence bands dicted bycatch rates $(\geq 0.1$ loggerhead per metric ton landed) (Appendix 1). These trips were fishing predominantly south of $38^{\circ} \mathrm{N}$ latitude (Figs. $4 \& 5$ ). The majority of VTR trips $(62 \%)$ had low predicted bycatch rates $(\leq 0.001$ loggerhead per metric ton landed), and cumulatively, had a low amount of average estimated bycatch $(<1 \%$ or $n=3 / 350)$. Estimated bycatch ranged from a low of 43 loggerheads in 1995 to a high of 1018 in 1997 (Fig. 6).

\section{Exploration of sources of uncertainty}

Choice of sampling unit

When trip was used as the sampling unit, the same variables were selected in the best-fitting model as when haul was used as the sampling unit. Estimated dispersion value of the model when trip was used was 4.1, indicating that dispersion was mostly unaffected by the sampling unit. These results confirm that the model developed here using haul as a sampling unit can be applied to VTR data at the trip level, because factors affecting estimated bycatch rates do not differ when the sampling unit is haul or trip.

\section{Representativeness of VTR data}

Filling in missing VTR data with observer data resulted in similar bycatch estimates. Distributions of VTR and observer landings were slightly different with respect to latitude, mesh size, and SST; however, VTR data were an adequate representation of total fishing effort. In the southern mid-Atlantic, VTR landings across mesh size groups were more representative of dealer landings than observer landings, particularly in some sectors. When missing VTR were imputed using a completely different source, the bycatch estimate was barely outside the confidence interval of the first approach. Therefore, the method to fill in missing information to estimate total bycatch was considered robust.

\section{DISCUSSION}

The present study highlights areas and mesh sizes with elevated risk for loggerhead bycatch in US midAtlantic gillnet fisheries. The combination of fishing in low latitudes, in warm SST, and with large mesh had the largest effect on estimated bycatch rates. Extreme highest rates (i.e. $\geq 1.0$ loggerhead per metric ton landed) occurred below $36^{\circ} \mathrm{N}$ in waters $>15^{\circ} \mathrm{C}$, in nets with $>17.8 \mathrm{~cm}$ ( 7 inches) mesh, but accounted for 

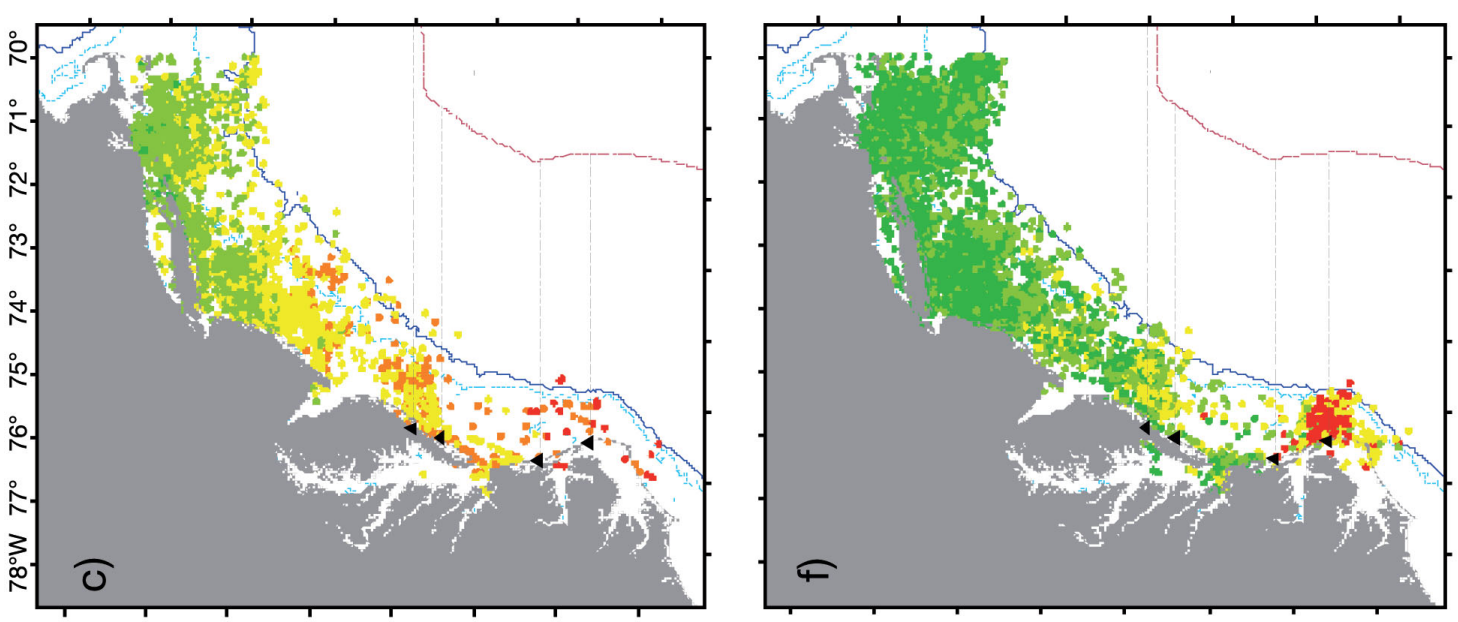

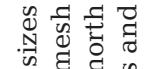

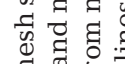

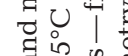

U $\vec{v} \stackrel{\Downarrow}{\Xi}$

ह

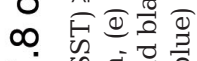

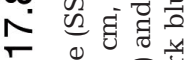

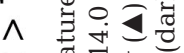

क

$\sum$ घ

赵

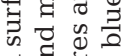

तृ

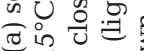
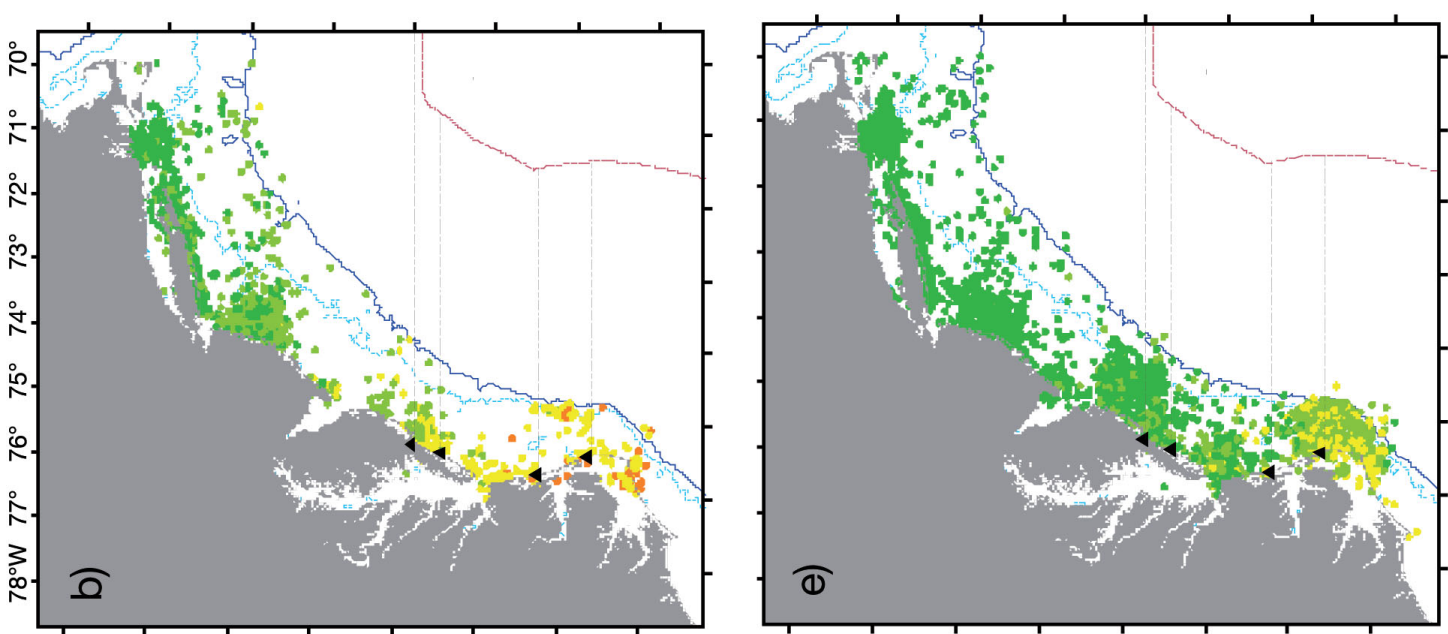

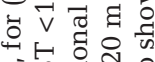

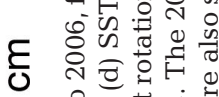

$\infty$ i

号

VI 出出专

둉 छ

क N

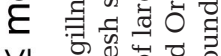

VI

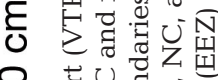

․

세

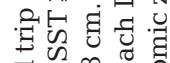

可出

वे $\vec{\wedge}$ चै
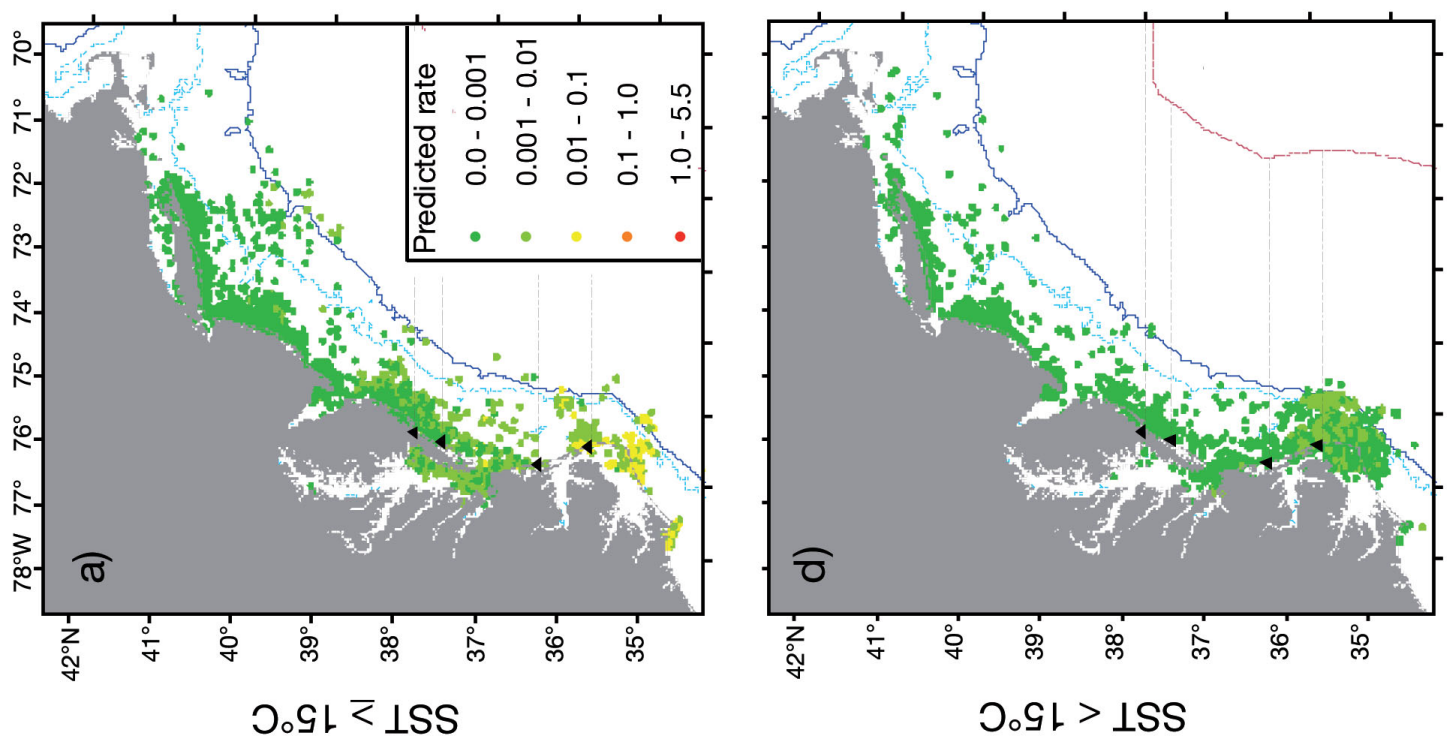

¿ $\infty . \stackrel{N}{0}$.

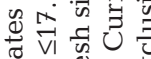

$\forall$ 면

चै चे

\&

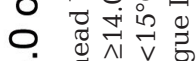

ป

$\checkmark$ S. N

$\checkmark$ 워

क व

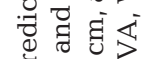

D $\infty$

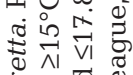

ชี

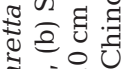

ปี घี घี

- 10 众

S) 


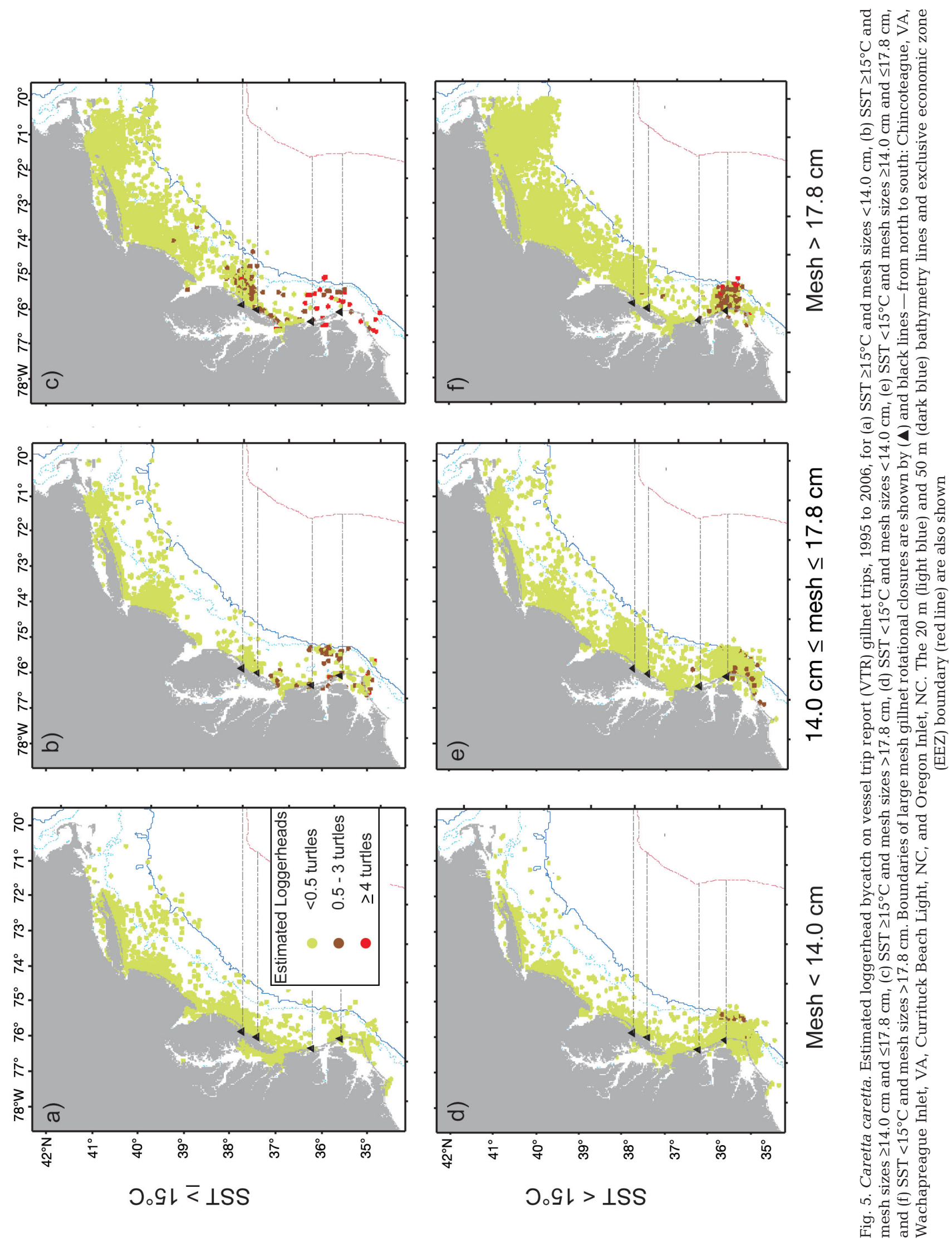




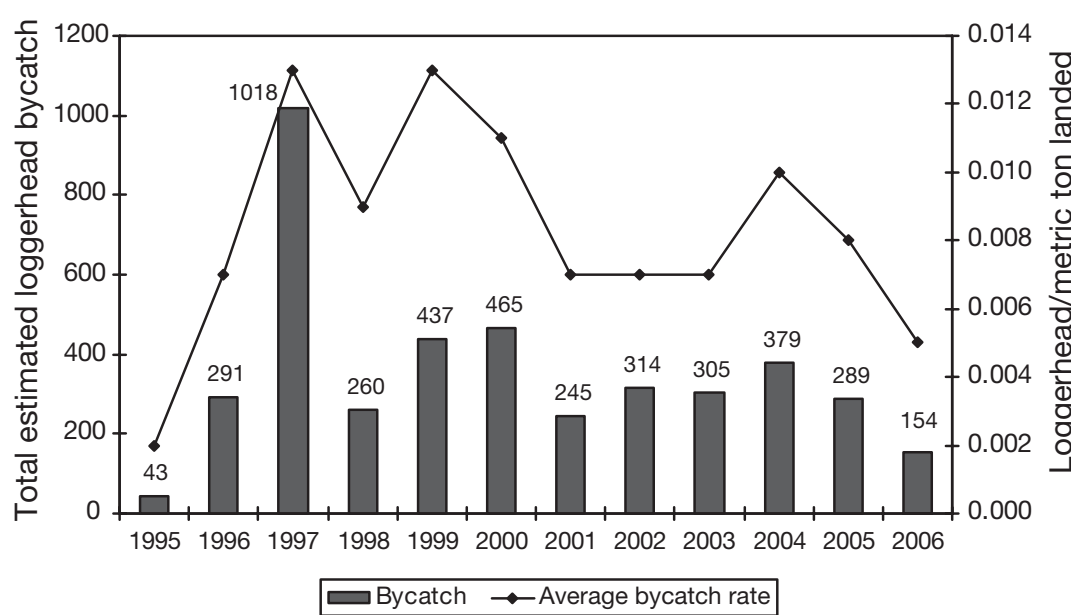

Fig. 6. Caretta caretta. Total estimated loggerhead bycatch and average estimated bycatch rates (loggerheads per metric ton of fish landed) by year in mid-Atlantic sink gillnet gear. Rates above each year represent an average over all vessel trip report (VTR) trips

$\sim 20 \%$ of the total estimated bycatch. Estimated bycatch rates were lower in other times and areas (i.e. in cooler waters or more northern latitudes) but total bycatch was still relatively high due to higher amounts of fishing effort. Estimated bycatch was generally higher in waters off $\mathrm{NC}$, and tended to be concentrated in that area when surface waters were cooler. In the vicinity of Cape Hatteras during late fall and early winter, the narrowness of the continental shelf and influence of the Gulf Stream concentrate turtles, making them more susceptible to fishery interactions (Epperly et al. 1995).

The largest bycatch reduction could potentially be achieved in the southern mid-Atlantic below $38^{\circ} \mathrm{N}$, in large $(>17.8 \mathrm{~cm})$ and medium $(14$ to $17.8 \mathrm{~cm})$ mesh gillnets. About $86 \%$ of the estimated bycatch occurred in this region and these mesh sizes, on trips constituting $30 \%$ of the total VTR landings. Some turtle conservation measures, however, are already in place in the southern mid-Atlantic. Large-mesh gillnet fishing has been prohibited on an annual basis since 2002 through a series of rolling closures designed to reduce bycatch of sea turtles. Areas are closed on a 'rolling' schedule to coincide with the probability of sea turtles in the area based on SSTs. The first rolling closure for gillnets with mesh $15.2 \mathrm{~cm}$ (6 inches) or greater was implemented in May 2000 for 30 d. There were no closures in 2001, but in 2002, rolling closures were implemented on an annual basis for gillnetters using mesh greater than $20.3 \mathrm{~cm}$ (8 inches) (subsequently reduced to $17.8 \mathrm{~cm}$ [7 inches] in mid-2006). Presently, waters south of Oregon Inlet to the NC and South Carolina border are closed year-round, and waters north of Oregon Inlet to Chincoteague, Virginia are closed to fishing for the year by mid-April.
These rolling closures for large-mesh gillnets did not eliminate loggerhead bycatch. During the period 2002 to 2006, when rolling closures were in place on an annual basis, 52\% ( $\mathrm{n}=149 / 288$ average over 2002 to 2006) of the estimated bycatch occurred in mesh smaller than $17.8 \mathrm{~cm}$ south of $38^{\circ} \mathrm{N}$, and in mesh larger than $17.8 \mathrm{~cm}$ north of $38^{\circ} \mathrm{N}$. The closures do not encompass mesh sizes smaller than $17.8 \mathrm{~cm}$, nor areas north of $38^{\circ} \mathrm{N}$. The current rolling closures are likely reducing the probability that loggerheads are captured south of $38^{\circ} \mathrm{N}$ in large-mesh gear because they are placed in areas that historically had high bycatch rates. However, other opportunities to reduce bycatch exist in smaller mesh gear, and north of the northern-most boundary of the current rolling closure.

Since 1997, when the estimated bycatch of loggerheads was highest, estimated bycatch has decreased considerably. Trends in the annual estimated bycatch fluctuated between 1998 and 2006, though by 2006 bycatch was $85 \%$ lower than 1997 levels. The present analysis cannot attribute the decline to any one factor because it does not fully examine trends in the abundance and distribution of sea turtles, nor the suite of regulations and market conditions affecting annual patterns of fishing effort. Estimated loggerhead bycatch has decreased, though it still continues. Population assessments may help shed light on the risk of current bycatch levels.

Population-level impacts on loggerheads could be pronounced from multiple fisheries interacting with loggerheads in the same spatial and temporal region, affecting the same life stage. Stage class models suggest that the long-term survivability of loggerhead sea turtles is sensitive to mortality at immature life stages (Crouse et al. 1987). Hundreds of loggerhead turtles are incidentally captured in mid-Atlantic scallop dredge gear (average of 310 turtles $\mathrm{yr}^{-1}$ from 2003 to 2005; Murray 2004, 2005, 2007), in pelagic longline gear (average of 93 turtles $\mathrm{yr}^{-1}$ from 2005 to 2007; Fairfield-Walsh \& Garrison 2006, 2007, Fairfield \& Garrison 2008), and in mid-Atlantic bottom otter trawl gear (average of 616 turtles $\mathrm{yr}^{-1}$ from 1996 to 2004; Murray 2006). Studies suggest that these fisheries impact large juveniles, the same life stage affected in the mid-Atlantic sink gillnet fishery. Loggerheads captured in the sea scallop dredge fishery averaged $\sim 78 \mathrm{~cm}$ CCL (Haas et al. 2008); those captured in Atlantic longline fisheries averaged 53 to $74 \mathrm{~cm}$ over 3 different studies (Lewison \& Crowder 2007); those captured in the summer flounder trawl fishery off NC averaged $62 \mathrm{~cm}$ (Epperly et al. 1995). About $80 \%$ of the ob- 
served loggerhead bycatch in the mid-Atlantic gillnet fishery had low reproductive values $(<0.2)$, relative to adults at or near the onset of sexual maturity (Wallace et al. 2008). However, the cumulative impact on the population from multiple fisheries interacting with juvenile loggerheads is likely larger than the sink gillnet fishery alone.

\section{CONCLUSIONS}

The present study represents the first comprehensive examination of sea turtle bycatch in sink gillnet gear in the US mid-Atlantic region. It contributes information on the total magnitude, species composition, mortality levels, and life stage of bycaught turtles in gillnet gear, to help parameterize population models and to inform conservation management strategies. This bycatch estimate of loggerheads in mid-Atlantic gillnet gear will also help contribute to cumulative bycatch assessments across multiple gear types (Moore et al. 2009).

In summary, turtles were observed in the sink gillnet fishery throughout the year over mid-Atlantic shelf waters from Cape Cod to NC. The estimated average annual bycatch was 350 loggerheads in gillnet fisheries from 1995 to 2006. About $40 \%$ of the observed loggerheads were dead, and $\sim 80 \%$ of observed loggerheads were immature animals. Green, Kemp's ridley, and leatherback turtles were also caught incidentally in gillnet gear in the mid-Atlantic region, but the observed numbers were too low to estimate the total amount of fishery-wide bycatch. Further, loggerhead bycatch rates and total estimated bycatch were characterized and depicted to identify areas where bycatch reduction can potentially be achieved.

Acknowledgements. Thanks to H. Haas and F. Serchuk for their constructive criticisms of this work, M. Warden for help in processing the observer data and assessing the quality of VTR data, C. Orphanides for help in obtaining remotely sensed environmental data and assessing the quality of VTR data, A. Bianchi for providing NCDMF data, the many observers who collected valuable fisheries information from the field, and 2 anonymous reviewers.

\section{LITERATURE CITED}

Brazner JC, McMillan J (2008) Loggerhead turtle (Caretta caretta) bycatch in Canadian pelagic longline fisheries: relative importance in the western North Atlantic and opportunities for mitigation. Fish Res 91:310-324

Burnham KP, Anderson DR (2002) Model selection and multimodal inference: a practical information-theoretic approach, 2nd edn. Springer-Verlag, New York
Crouse DT, Crowder LB, Caswell H (1987) A stage-based population model for loggerhead sea turtles and implications for conservation. Ecology 68:1412-1423

Epperly SP, Braun J, Chester AJ, Cross FA, Merriner JV, Tester PA (1995) Winter distribution of sea turtles in the vicinity of Cape Hatteras and their interactions with the summer flounder trawl fishery. Bull Mar Sci 56:547-568

Fairfield CP, Garrison LP (2008) Estimated bycatch of marine mammals and sea turtles in the U.S. Atlantic pelagic longline fleet during 2007. NOAA Tech Memo NOAA NMFSSEFSC-572. Southeast Fisheries Science Center, NOAA, Miami, FL

Fairfield-Walsh CP, Garrison LP (2006) Estimated bycatch of marine mammals and sea turtles in the U.S. Atlantic pelagic longline fleet during 2005. NOAA Tech Memo NOAA NMFS-SEFSC-539. Southeast Fisheries Science Center, NOAA, Miami, FL

Fairfield-Walsh CP, Garrison LP (2007) Estimated bycatch of marine mammals and sea turtles in the U.S. Atlantic pelagic longline fleet during 2006. NOAA Tech Memo NOAA NMFS-SEFSC-560. Southeast Fisheries Science Center, NOAA, Miami, FL

> Gardner B, Sullivan PJ, Morreale SJ, Epperly SP (2008) Spatial and temporal statistical analysis of bycatch data: patterns of sea turtle bycatch in the North Atlantic. Can J Fish Aquat Sci 65:2461-2470

> Haas H, LaCasella E, LeRoux R, Milliken H, Hayward B (2008) Characteristics of sea turtles incidentally captured in the U.S. Atlantic sea scallop fishery. Fish Res 93: 289-295

Hardin J, Hilbe J (2001) Generalized linear models and extensions. Stata Press, College Station, TX

Harrell FE Jr (2001) Regression modeling strategies. Springer-Verlag, New York

Hastie TJ, Tibshirani RJ (1990) Generalized additive models. Chapman \& Hall, New York, NY

> Howell EA, Kobayashi DR, Parker DM, Balazs GH, Polovina JJ (2008) TurtleWatch: a tool to aid in the bycatch reduction of loggerhead turtles Caretta caretta in the Hawaiibased longline fishery. Endang Species Res 5:267-278

> Lewison RL, Crowder LB (2007) Putting longline bycatch of sea turtles into perspective. Conserv Biol 21:79-86

Marine Turtle Specialist Group (1996a) Caretta caretta. In: IUCN (2008). 2008 IUCN Red List of Threatened Species. www.iucnredlist.org (accessed 16 March 2009)

Marine Turtle Specialist Group (1996b) Lepidochelys kempii. In: IUCN (2008) 2008 IUCN Red List of Threatened Species. www.iucnredlist.org (accessed 16 March 2009)

McCracken ML (2004) Modeling a very rare event to estimate sea turtle bycatch: lessons learned. NOAA Tech Memo NMFS-PIFSC-3. Pacific Islands Fisheries Science Center, NOAA, Honolulu, HI

Moore JM, Wallace B, Lewison RL, Zydelis R, Cox T, Crowder L (2009) A review of marine mammal, sea turtle and seabird bycatch in USA fisheries and the role of policy in shaping management. Mar Policy 33:435-451

Murray KT (2004) Bycatch of sea turtles (Caretta caretta) in the mid-Atlantic sea scallop (Placopecten magellanicus) dredge fishery during 2003, 2nd edn. Reference document 04-11. Northeast Fisheries Science Center, NOAA, Woods Hole, MA. Available at www.nefsc.noaa.gov/nefsc/ publications/crd/crd0411/

Murray KT (2005) Total bycatch estimate of loggerhead turtles (Caretta caretta) in the 2004 Atlantic sea scallop (Placopecten magellanicus) dredge fishery. Reference document 05-12. Northeast Fisheries Science Center, NOAA, Woods Hole, MA. Available at www.nefsc.noaa. 
gov/nefsc/publications/crd/crd0512/

Murray KT (2006) Estimated average annual bycatch of loggerhead sea turtles (Caretta caretta) in U.S. mid-Atlantic bottom otter trawl gear, 1996-2004. Reference document 06-19. Northeast Fisheries Science Center, NOAA, Woods Hole, MA. Available at www.nefsc.noaa.gov/nefsc/ publications/crd/crd0619/

Murray KT (2007) Estimated bycatch of loggerhead sea turtles (Caretta caretta) in U.S. mid-Atlantic scallop trawl gear, 2004-2005, and in sea scallop dredge gear, 2005. Reference document 07-04. Northeast Fisheries Science Center, NOAA, Woods Hole, MA. Available at www.nefsc. noaa.gov/nefsc/publications/crd/crd0704/

NMFS (National Marine Fisheries Service) and USFWS (US Fish and Wildlife Service) (2008) Recovery plan for the Northwest Atlantic population of the loggerhead sea turtle (Caretta caretta), 2nd revision. NMFS, NOAA, Silver Spring, MD. Available at www.nmfs.noaa.gov/pr/ recovery/plans.htm\#turtles

Palka DL, Rossman MC (2001) Bycatch estimates of coastal bottlenose dolphin (Tursiops truncates) in U.S. midAtlantic gillnet fisheries for 1996 to 2000. Reference document 01-15. Northeast Fisheries Science Center, NOAA, Woods Hole, MA. Available at www.nefsc.noaa. gov/psb/pubs/0115.pdf

Peduzzi P, Concato J, Kemper E, Holford TR, Feinstein AR (1996) A simulation study of the number of events per variable in logistic regression analysis. J Clin Epidemiol 49(Issue 12):1373-1379

Rago PJ, Wigley SE, Fogarty MJ (2005) NEFSC bycatch estimation methodology: allocation, precision, and accuracy. Reference document 05-09. Northeast Fisheries Science Center, NOAA, Woods Hole, MA. Available at www.nefsc. noaa.gov/nefsc/publications/crd/crd0509/

Sarti Martinez AL (2000) Dermochelys coriacea. In: IUCN
(2008) 2008 IUCN Red List of Threatened Species. www. iucnredlist.org (accessed 16 March 2009)

Seminoff JA (2004) Chelonia mydas. In: IUCN (2008) 2008 IUCN Red List of Threatened Species. www.iucnredlist. org (accessed 16 March 2009)

Sims M, Cox T, Lewison R (2008) Modeling spatial patterns in fisheries bycatch: improving bycatch maps to aid fisheries management. Ecol Appl 18:649-661

Steve C, Gearhart J, Gorggaard D, Sabo L, Hohn AA (2001) Characterization of North Carolina commercial fisheries with occasional interactions with marine mammals. NOAA Tech Memo NMFS-SEFSC-458. Southeast Fisheries Science Center, NOAA, Miami, FL

Stokes ME, Davis CS, Koch GG (1995) Categorical data analysis using the SAS System. SAS Institute, Cary, NC

US Department of Commerce (2002a) Sea turtle conservation; restrictions to fishing activities. Fed Regist 67: 71895-71899

US Department of Commerce (2002b) Sea turtle conservation; restrictions to fishing activities. Fed Regist 67: 56931-56934

Wallace BP, Heppell SS, Lewison RL, Kelez S, Crowder LB (2008) Impacts of fisheries bycatch on loggerhead turtles worldwide inferred from reproductive value analyses. J Appl Ecol 45:1076-1085

Warden ML, Orphanides CD (2008) Preparation of the Northeast Fisheries Observer Program gillnet data for use in bycatch analyses of protected species. Reference document 08-17. Northeast Fisheries Science Center, NOAA, Woods Hole, MA. Available at www.nefsc.noaa.gov/ nefsc/publications/crd/crd0817/

Witzell WN (1999) Distribution and relative abundance of sea turtles caught incidentally by the U.S. pelagic longline fleet in the western North Atlantic Ocean, 1992-1995. Fish Bull (Wash DC) 97:200-211 
Appendix 1. Caretta caretta. Model-predicted bycatch rates and estimated annual average loggerhead bycatch on vessel trip report (VTR) sink gillnet trips. SST = sea surface temperature; small mesh: <14 cm; medium mesh: 14 to $17.8 \mathrm{~cm}$; large mesh:

$>17.8 \mathrm{~cm} ;$ nd $=$ no VTR trips in the respective rate category

\begin{tabular}{|c|c|c|c|c|c|c|}
\hline Predicted rate & $\begin{array}{l}\text { Latitude } \\
\qquad\left({ }^{\circ} \mathrm{N}\right)\end{array}$ & $\begin{array}{l}\mathrm{SST} \\
\left({ }^{\circ} \mathrm{C}\right)\end{array}$ & Mesh & $\begin{array}{l}\% \text { of total } \\
\text { VTR trips }\end{array}$ & $\begin{array}{l}\% \text { of total } \\
\text { VTR landings }\end{array}$ & $\begin{array}{l}\text { Average estimated } \\
\text { bycatch 1995-2006 }\end{array}$ \\
\hline Total & $\leq 38$ & $\begin{array}{l}\geq 15 \\
<15\end{array}$ & $\begin{array}{l}\text { Small } \\
\text { Medium } \\
\text { Large } \\
\text { Small } \\
\text { Medium } \\
\text { Large } \\
\text { Small } \\
\text { Medium } \\
\text { Large } \\
\text { Small } \\
\text { Medium } \\
\text { Large }\end{array}$ & $\begin{array}{c}13 \\
3 \\
<1 \\
5 \\
10 \\
23 \\
2 \\
\text { nd } \\
\text { nd } \\
4 \\
2 \\
<1 \\
\mathbf{6 2}\end{array}$ & $\begin{array}{c}4 \\
1 \\
1 \\
2 \\
6 \\
14 \\
2 \\
\text { nd } \\
\text { nd } \\
13 \\
6 \\
1 \\
\mathbf{5 0}\end{array}$ & $\begin{array}{c}\text { nd } \\
<1 \\
<1 \\
<1 \\
<1 \\
1 \\
<1 \\
\text { nd } \\
\text { nd } \\
1 \\
<1 \\
<1 \\
\mathbf{3}\end{array}$ \\
\hline Total & $>38$ & $\begin{array}{l}\geq 15 \\
<15\end{array}$ & $\begin{array}{l}\text { Small } \\
\text { Medium } \\
\text { Large } \\
\text { Small } \\
\text { Medium } \\
\text { Large } \\
\text { Small } \\
\text { Medium } \\
\text { Large } \\
\text { Small } \\
\text { Medium } \\
\text { Large }\end{array}$ & $\begin{array}{c}<1 \\
3 \\
7 \\
\text { nd } \\
<1 \\
11 \\
3 \\
<1 \\
\text { nd } \\
1 \\
2 \\
1 \\
28\end{array}$ & $\begin{array}{c}<1 \\
1 \\
4 \\
\text { nd } \\
<1 \\
7 \\
5 \\
<1 \\
\text { nd } \\
5 \\
10 \\
2 \\
\mathbf{3 5}\end{array}$ & $\begin{array}{c}<1 \\
1 \\
5 \\
\text { nd } \\
<1 \\
5 \\
4 \\
1 \\
\text { nd } \\
3 \\
10 \\
2 \\
\mathbf{3 1}\end{array}$ \\
\hline $0.01-0.1$ & $\leq 38$ & $\begin{array}{l}\geq 15 \\
<15 \\
\geq 15 \\
<15\end{array}$ & $\begin{array}{l}\text { Small } \\
\text { Medium } \\
\text { Large } \\
\text { Small } \\
\text { Medium } \\
\text { Large } \\
\text { Small } \\
\text { Medium } \\
\text { Large } \\
\text { Small } \\
\text { Medium } \\
\text { Large }\end{array}$ & $\begin{array}{c}0 \\
<1 \\
5 \\
\text { nd } \\
\text { nd } \\
<1 \\
1 \\
<1 \\
<1 \\
0 \\
<1 \\
1 \\
1 \\
\mathbf{9}\end{array}$ & $\begin{array}{c}0 \\
<1 \\
3 \\
\text { nd } \\
\text { nd } \\
<1 \\
1 \\
2 \\
<1 \\
0 \\
3 \\
3 \\
\mathbf{1 3}\end{array}$ & $\begin{array}{c}0 \\
<1 \\
17 \\
\text { nd } \\
\text { nd } \\
1 \\
7 \\
15 \\
13 \\
<1 \\
15 \\
25 \\
93\end{array}$ \\
\hline Total & $\leq 38$ & $\begin{array}{l}\geq 15 \\
<15 \\
\geq 15 \\
<15\end{array}$ & $\begin{array}{l}\text { Small } \\
\text { Medium } \\
\text { Large } \\
\text { Small } \\
\text { Medium } \\
\text { Large } \\
\text { Small } \\
\text { Medium } \\
\text { Large } \\
\text { Small } \\
\text { Medium } \\
\text { Large }\end{array}$ & $\begin{array}{l}\text { nd } \\
\text { nd } \\
<1 \\
\text { nd } \\
\text { nd } \\
\text { nd } \\
<1 \\
<1 \\
<1 \\
\text { nd } \\
\text { nd } \\
<1 \\
\mathbf{1}\end{array}$ & $\begin{array}{l}\text { nd } \\
\text { nd } \\
<1 \\
\text { nd } \\
\text { nd } \\
\text { nd } \\
<1 \\
<1 \\
<1 \\
\text { nd } \\
\text { nd } \\
1 \\
2\end{array}$ & $\begin{array}{c}\text { nd } \\
\text { nd } \\
3 \\
\text { nd } \\
\text { nd } \\
\text { nd } \\
<1 \\
35 \\
66 \\
\text { nd } \\
\text { nd } \\
45 \\
\mathbf{1 4 9}\end{array}$ \\
\hline $1.0-5.5$ & $>38$ & $\begin{array}{l}\geq 15 \\
<15\end{array}$ & $\begin{array}{l}\text { Small } \\
\text { Medium } \\
\text { Large } \\
\text { Small } \\
\text { Medium } \\
\text { Large } \\
\text { Small } \\
\text { Medium } \\
\text { Large } \\
\text { Small } \\
\text { Medium } \\
\text { Large }\end{array}$ & $\begin{array}{l}\text { nd } \\
\text { nd } \\
\text { nd } \\
\text { nd } \\
\text { nd } \\
\text { nd } \\
\text { nd } \\
<1 \\
<1 \\
\text { nd } \\
\text { nd } \\
\text { nd }\end{array}$ & $\begin{array}{c}\text { nd } \\
\text { nd } \\
\text { nd } \\
\text { nd } \\
\text { nd } \\
\text { nd } \\
\text { nd } \\
0 \\
<1 \\
\text { nd } \\
\text { nd } \\
\text { nd }\end{array}$ & $\begin{array}{l}\text { nd } \\
\text { nd } \\
\text { nd } \\
\text { nd } \\
\text { nd } \\
\text { nd } \\
\text { nd } \\
<1 \\
74 \\
\text { nd } \\
\text { nd } \\
\text { nd }\end{array}$ \\
\hline Total & & & & $<1$ & $<1$ & 74 \\
\hline Grand total & & & & 100 & 100 & 350 \\
\hline
\end{tabular}

